\title{
Masculinities, History and Cultural Space: Queer Emancipative Thought in Jamie O'Neill's At Swim, Two Boys
}

\section{ABSTRACT}

At Swim, Two Boys, a 2001 novel by Jamie O’Neill, tells a story of gay teen romance in the wake of the Easter Rising. This paper considers the ways in which the characters engage in patterns of masculine behaviour in a context that excludes queer men, and the rhetorical effect of transgressive strategies to form a coherent identity. These patterns include involvement with the masculine and heteronormative nationalist movement, as well as a regime of physical exercise, and a religious upbringing in $20^{\text {th }}$-century Ireland. The strategies of broadening the practices of masculinity include their renegotiation and redefinition, as well as attempts to (re)construct the Irish and the gay canons of history and literature. These strategies, as exemplified by character development, become a rhetorical basis for the novel's main argument for inclusiveness. This analysis deals with the central metaphors of space and continuity in the novel in the light of a struggle between identities. It also observes the tradition of parallels drawn between the emasculated position of the gay man and the Irish man at the beginning of the $20^{\text {th }}$ century, and O'Neill's rhetorical deployment of the shared telos in construction of a coherent gay Irish revolutionary identity.

Keywords: Jamie O’Neill, queer, masculinity, At Swim, Two Boys, Easter Rising. 
Ideas of power and masculinity are closely linked in the patriarchal order. The latter is a social phenomenon related to gender performances rather than an intrinsic quality; thus, it is not as much possessed as it is perceived, constituting an unstable element in power relations. It follows that a perceived lack of masculinity results in a state of powerlessness, and attempts to change power relations are closely linked to either (re)claiming masculinity or subverting its privileged status. The dynamics between masculinity and power, manifest as a cultural space, provide a thematic link between Irishness and homosexuality in Jamie O'Neill's At Swim, Two Boys, a historical bildungsroman telling the story of two gay teenagers set against the backdrop of masculinity performances leading up to and during the Easter Rising.

In order to reclaim power, both the gay man and the Irishman had to overcome cultural constructs according to which they lacked masculinity. Historically, the Irishman was emasculated by his subjugation and his circumstances were in that way similar to those of the Jewish man:

Both Jewish and Irish cultures were greatly affected by their weakness vis-à-vis the stronger majority, and Jewish and Irish men faced some conceptually similar stereotypes about their supposed deficiencies. Zionism, like Irish nationalism, was also a concerted effort to refute popular racial stereotypes and create a more prideful image of Jewish strength and power. (Beatty 5)

Attempts to reclaim masculinity by the Irish took an indirect form of Gaelic Revival, and manifested through a number of direct power struggles, such as the Easter Rising. The study, reinvention and popularization of Irish history and tradition played a critical part in the formation of Irish national identity which was a precondition for any independence claim.

There are some striking parallels between the struggle of the Irish at the beginning of the $20^{\text {th }}$ century and the gay rights movement in the $1960 \mathrm{~s}$ and '70s. First and foremost, the gay man used to be perceived as lacking masculinity:

Patriarchal culture has a simple interpretation of gay men: they lack masculinity.... The interpretation is obviously linked to the assumption our culture generally makes about the mystery of sexuality, that opposites attract. If someone is attracted to the masculine, then that person must be feminine if not in the body, then somehow in the mind. (Connell 143)

The rearrangement of this social construct started with the reconstruction of a canon, a discovery of the ages-old cultural heritage, spanning from Ancient Greece and the Roman Empire, through the traditions of homosexuality persevering not only in Europe, but also in the Middle East, China and 
Japan, to the acknowledgement of the $20^{\text {th }}$-century martyrdom of the pink triangle Holocaust victims. ${ }^{1}$ These history studies fueled the formation of a shared identity, the defense of which resulted in the Stonewall Riots in 1969 , commonly recognized as the beginning of gay liberation, a non-violent attempt to rearrange heteronormative power relations.

More than a historical parallel, however, the Irish and the gay identity claims were in active interplay ever since the stable formation of the latter at the end of the $19^{\text {th }}$ century. First and foremost, the trial of Oscar Wilde resulted in the introduction of the gay subject into public discourse. Wilde, an Irish writer known for his witty, dandy style was accused of gross indecency, a legal euphemism for homosexual sex. The publicity his trial acquired, as well as its repressive outcome, forced public recognition of Wilde, his writing, and his style as elements of the homosexual code, which for centuries had circulated unrecognized in heteronormative culture. Another case is Roger Casement, an Irish human rights activist and a supporter of Irish independence, who was caught while aiding the organization of the Easter 1916 Rising and arrested for treason against the British crown. His actions and speeches acquired a queer context once his private diaries were investigated during the trial and an account of his homosexual love life became public knowledge.

Casement is important for contemporary queer literature not only as a historical figure, but also as a textual context. In James Joyce's masterpiece Ulysses Casement's biography is a significant background for the Cyclops chapter. According to Patrick R. Mullen, the scene of Bloom's conversation with the citizen draws upon Casement's "Speech from the Dock," representing the exclusionary practices of pure Irish nationalism and a queer idea of affinitive diverse Irish identities:

With the authenticated chastity of Irish identity achieved, the reactionary project of cultural, ethnic, and political verification can begin thus the citizen's fanatical inquisition of Bloom. The bugger's tool stages a vital multiplicity in which such verification makes no sense. Through this affective multiplicity Casement becomes a figure of intelligent sympathy, an affective tool, that allows Joyce to dissect critically the contradictions of the Irish, colonial situation. (108)

Joyce uses the figure of Casement to destabilize the idea of Irishness and to open it to a queer reinterpretation that is at odds with a hermetic Catholic, nationalist discourse.

1 On various traditions of homosexuality, and reconstruction of a gay canon, see Gregory Woods, A History of Gay Literature: The Male Tradition (New Haven: Yale UP, 1999). 
Jamie O'Neill follows this tradition, as he draws a parallel between gay oppression and the Irish colonized situation in At Swim, Two Boys by telling the story of two gay teenagers and of how their national and sexual identities form. Doyler Doyle and Jim Mack engage in masculinity performances related to nationalism and Catholicism, both strong signs of Irishness, while they explore their sexual identities. The dynamics of participation in and deviation from prescriptive religious norms in the Irish context are visible in the title of the novel itself, as it relates to Flann O'Brien's At Swim-Two-Birds, and, by extension, to the myth of Buile Suibhne, the prototypical Irish text about dissent against religion and about deviation from the norm. The main conflicts in the novel are not the Irish struggle against the British Empire, or the gay men rebelling against the forces that exclude them; rather, these elements are mostly suggested by the internal conflicts of the characters who are torn between their cultural understandings of masculinity performances and the sexual realities of their bodies.

One of the masculinity performances discussed in the novel is a religious practice. The novel presents the Catholic Church as an institution that disciplines society against all breaches in heteronormative perspective. At the beginning of the $20^{\text {th }}$-century religious institutions were still powerful and closely connected to the state, and they bore responsibility in the upkeep of patriarchy and the exclusion of gay people:

The Greek era's relative tolerance for select forms of homosexual activity ... gave way to very harsh prescriptions against all sexual activity outside of heterosexual marriage during the Christian era.... Fueling this escalating persecution was the distinct fear that homosexual activity within religious communities would threaten the involved individuals primary allegiance to the church hierarchy. . . . Christian theocratic states [were] determined to repudiate pagan/Greek activities, enforce a gender order that kept women in a state of sexual and social servitude to men (and men channeling their sexual energies into creating new church members), and divide individuals into clear-cut domestic units that rendered political and social control much easier to achieve and maintain. (Hall 27-28)

As such, the Catholic Church plays a great role in the preservation of hegemonic masculinity. As the main characters are involved in religious tradition through their upbringing, the dynamics between their sexual development and larger disciplinary practices are crucial to the formation of their identities.

At the beginning of the novel, Jim Mack undergoes a religious education when he prepares to join the Brothers of Presentation. He is motivated to pursue this path because he is an orphan ashamed of his sexuality (at 
the time unspecified as homosexuality): "A brother took vows, and if he kept those vows his mother need never feel shame before the angels" (O'Neill 106). The Catholic Church is identified as a heteronormative institution that practices its disciplinary power through control over the bodies and sexual lives of its members. However, as the story unfolds, Jim's mechanisms of repression are challenged when his childhood friend, Doyler, returns to their hometown of Glasthule. Doyler is a socialist and an uneducated, working-class boy. Jim recognizes him as an unfit companion:

There was plenty about bad company, however, in most the books they used at Presentation. In particular a manual called Christian Politeness which described the proper deportment of a Catholic gentleman. . . . Doyler might have posed for the thou-shalt-nots. His hands wouldn't settle, but swept along a wall or slapped against any lamppost he passed. He scrunched stones underfoot or scooted them away as though they posed an obstruction. According to Christian Politeness, the eyes were the windows of the soul: Doyler's rarely rested: proof of a giddy and unstable character. (95)

These observations do not discourage Jim from befriending Doyler. As a result, the boy is torn between the new friendship and the old ambition. Challenges arise when Doyler tries to convince his friend to skip Mass so they can swim together, having the popular bathing place all to themselves, or when he enters the chambers of Jim's mentor at school. Brother Polycarp, who embodies the religious disciplinary practice, has for a long time been disapproving of Doyler and at this point he decides to challenge his protégé in the hope of intimidating him into a denouncement of the troublesome friendship:

"Is this vulgarian to do with you?"

Jim felt the burning on his face. "He's my friend, Brother. You know that already."

"Pal o' me heart," said Doyler.

Jim saw himself weighed in the balance, then bitterly Brother Polycarp said, "And the half of your soul that is damned. Out of my sight, the both of ye." (139)

Jim's resistance leads to further disagreements with Brother Polycarp and to a shift in the boy's perception of the mentor, whom Jim begins to deem “an ignorant fool” (153) As a result, Jim chooses to fulfill Doyler's wish and skip Mass in order to swim together. Thus, the friendship between the boys begins to dissolve Jim's engagement with a heteronormative masculinity pattern of Christian practice even before the boys' rapport acquires a consciously homoerotic dimension. 
However, this first change in Jim's behavior does not resolve the underlying internal conflict. Jim might no longer plan to escape his sexuality through the celibate life he intended to live, but he remains sexually repressed. When halfway through the novel Doyler, publicly denounced by a priest as a socialist, leaves Glasthule in order to join the revolutionaries, Jim is left alone and confused about his sexuality. As a result, the boy goes through a sexual initiation with a random soldier. Dumbfounded, he seeks repentance in confession, but the religious practice fails him. He discovers he lacks words to express what he has done and the priest assumes the boy simply slept with a woman and promptly grants him absolution. Jim finds himself in a discursive void, unable to see any relevance of his bodily experience to culture, and believes his sin to be unique:

$[\mathrm{N}]$ o sin had been named that covered his wickedness. What he had done was so sinful, so unspeakably so, of such aberrance, to such unnatural degree, that the Church, for all her far-seeing and deep-searching, her vision and penetration, had not thought to provide against its happening. It was an extraordinary thing that he should have found this chink: he, the son of a Glasthule huckster, of a quakebuttock, a quakebuttock himself, should in the majestic vault of Christendom a flaw have found.

A rhetorical quality of these passages lies not only in the forceful self-hatred that inspires an empathetic reaction in the reader, but also in the clarity of Jim's mistake. He is far from being the first to engage in homosexual sex, and the Catholic Church is far from being unaware of that practice. However, cultural censorship renders Jim entirely oblivious to any history of homosexuality that might enable the formation of his sexual identity.

Precisely for that reason, Jim's friendship with the third main character in the novel, Anthony MacMurrough, has a healing effect on the boy. MacMurrough is an older man, an aristocrat, who was imprisoned for some time because of his homosexuality. He assumes the role of a mentor for Jim, as they talk about past cultural contexts and institutions established to give homosexual relationships some cultural space. The institutions and the stories of homosexuality include contexts that Jim has already been aware of, such as those from Ancient Greece, but with the censorship practices brought to light:

"The entire world grows up on those stories. Only difference is, I told him the truth, that they were lovers, humping physical fellows." Yes, and Jim had grasped instinctively that significance: that more than stories, they were patterns of the possible. And I think, how happier my 
boyhood should have been, had somebody-Listen, boy, listen to my tale- thought to tell me the truth. Listen while I tell you, boy, these men loved and yet were noble. (607)

Through this education, O'Neill underlines the relevance of history in the process of identity formation. The suppression of gay history is a result of the homophobic structures of power, which are set to evoke the very self-loathing conundrum in which Jim was stuck. Teaching the boy about his history undoes this disciplinary practice and frees him. This is a close parallel to various undertakings intended to nurture Irish culture which are discussed in the novel, such as teaching the Gaelic language or folk songs. O'Neill posits the two processes of identity formation in close vicinity, presenting education as necessary in overcoming the institutional practices of shaming which can then result in the formation of a coherent identity regardless of the nature of that identity, be it national or sexual.

Curiously, their relationship not only informs Jim of gay history, but it also openly enacts the institution of pederasty from Ancient Greece, where the erastes, an adult male, teaches a youth, the eromenos, his student and beloved. Moreover, it parallels The Picture of Dorian Gray by Oscar Wilde, where Lord Henry also teaches young Dorian his own, non-normative values. Significantly, MacMurrough references Wilde on multiple occasions, showing his sense of affinity with the writer, who at the time has already become a powerful icon in the homosexual code. However, while Lord Henry's philosophy encourages Dorian to follow his inner desires and ultimately brings about his downfall, Anthony's guidance explains to Jim his own sexual experience and helps him to form a healthy, functional identity. Moreover, Anthony's desire for Jim is controlled and halted throughout the novel, departing from the education in hedonism presented in The Picture of Dorian Gray and presenting a possibility of a different non-normative guidance. The relationship of the boy and the aristocrat is connected both to the historical and the literary practices of signifying homosexuality, thus enacting the very ideas Jim learns about and forming their praxis.

The discovery of gay history also subverts the hegemonic understanding of male homosexuality as a lack of masculinity. The central metaphor of the novel, relevant in the context of the rising, is the Sacred Band of Thebes, an army of soldiers who were lovers and who would rather die than see their loved ones killed. This story is a radical transgression of a regular military masculinity practice: in this case homosexuality does not disqualify from engagement with it, but on the contrary, it is beneficial, as same-sex love is utilized to support a military virtue of loyalty. This transgression exemplifies the main rhetorical point of the book; it connects to the Irish 
historic setting, in which the Irishman, culturally constructed as unmasculine, lays an identity claim through a masculine practice of military struggle with a need to transgress the cultural construct of homosexuality as un-masculine in order to forge a coherent identity and claim space for gay people within culture.

MacMurrough's own way of thinking about his identity as a gay man and an Irishman is yet another example of this subversive approach to history. He tries to renegotiate the patriotic notions by toying with the idea of Irish identity and using provocative statements to infiltrate the nationalist discourse with the idea of homosexuality. He delights in public embarrassments occurring in Irish society: "I was thinking: Parnell and Wilde, the two great scandals of the age: both Irish. It's good to know Ireland can lead the world in something" (308). While the statement is clearly a joke, Oscar Wilde plays a major role in MacMurrough's mode of thinking about Ireland. Provocatively, he describes Wilde's story to a Catholic curate, presenting him as an Irish martyr, for the thrill of his listener's outrage at the unjust treatment of the writer. In another scene, asked if he is "an unspeakable of the Oscar Wilde sort" in a scene enacting a tableaux of coming out, MacMurrough responds: "if you mean I'm Irish, then the answer is yes" (309). In a similar manner to how Joyce uses the figure of Casement in Ulysses, O'Neill deploys Wilde in At Swim, Two Boys as a historical element destabilizing the meaning of Irishness and containing the parallel between the Irish position and the gay situation.

This parallel governs O'Neill's novel as a whole, as it constitutes an attempt to reclaim Irish history for gay people. Historically, the position of queerness in the Irish context has been determined through a colonial lens:
Alan Sinfeld (1994) has argued the late nineteenth century saw the association of "effeminacy" with homosexuality and the demonization of both in the course of the Wilde trials. Keeping in mind that the conflation of heterosexual maleness and "aggressive masculinity" as ideals were forming in this period, it is important to note that both the British colonial powers and the Irish nationalists were using the same language of "masculinity" and that both wrote homosexuality as a kind of foreign "pollution." (Conrad 127)

Homosexuality was conceptualized within the colonial framework as a foreign influence so that it could be distanced from the everyday experience of the Irish. Having gay protagonists participate in the Easter Rising, a foundational event for Irish national identity, and stressing Oscar Wilde's Irish nationality, allow for a reinterpretation of Irish history that 
is more inclusive of non-normative sexualities, in a similar manner to how MacMurrough's education allows the boys to reclaim history in general as theirs. Both Irish and gay histories of marginalization are on the one hand connected by emasculation, and on the other by "telos of liberation" (Conrad 126), that is an uneven fight against a stronger, oppressive enemy. Moreover, even the means to an end are similar, as O'Neill focuses on cultural aspects of nationalist discourse, i.e. the Gaelic Revival, which is paralleled by the boys' education in gay history.

The goal suggested by the rhetorical dimension of the novel also parallels the Irish identity claim, as it argues that it is necessary for gay people to have space-in this case not geographical space, but cultural. The representation of gay history serves as a foundation for the discussion of an inherently political argument between essentialist and constructionist ideas of homosexuality. MacMurrough presents the work of his mentor, Scrotes, to introduce this argument:

You asked me earlier were there many of us about. The question for my friend was, were there any of us at all. The world would say that we did not exist, that only our actions, our habits, were real, which the world called our crimes or our sins. But Scrotes began to think that we did indeed exist. That we had a nature our own, which was not another's perverted or turned to sin. Our actions could not be crimes, he believed because they were the expression of a nature, of an existence even. Which came first, he asked, the deed or the doer? And he began to answer that, for some, it was the doer. (O’Neill 283-84)

The speech reflects the shift in the understanding of sexuality that occurred in the $19^{\text {th }}$ century: a move from seeing same-sex desire as a singular act to the "invention of a homosexual," i.e. perceiving any sexual orientation as a stable quality of a person. MacMurrough's views here closely follow the identity politics of early gay activism, arguing that homosexuality is an effect of nature rather than nurture. This idea supports the claim for a cultural space for gay people and the argument against the deeply ingrained cultural perceptions of sexualities other than heterosexual as perverted and unnatural.

The discussion of disciplinary practices in the novel follows the emancipative logic of subverting and arguing against the juxtaposition of masculinity performances and homosexuality. One such pattern is Jim's self-loathing provoked by his religious upbringing. A similar repressive mechanism works against Doyler's early sexual liberty. Once the boy runs away from Glasthule and joins the army, he becomes constrained by the cultural expectations of what it means to be a soldier. Much like Jim, who did not imagine it possible for his performance of a Catholic man 
to allow for their friendship, now Doyler believes it impossible for their relationship to grow while he performs his duties: "I try not to think of him, only I can't get him off my mind. . . I try to make him go away, for I'm a soldier now and I'm under orders" (498). However, Jim, who becomes more and more interested in the revolution because of Doyler, does not see the two as mutually exclusive:

"We'll be asked to fight for Ireland, sure I know that."

"But what is Ireland that you should want to fight for it?"

"Sure I know that too.". .. "It's Doyler," he said.

"Doyler is your country?"

"It's silly, I know. But that's how I feel. I know Doyler will be out, and where would I be but out beside him? I don't hate the English and I don't know do I love the Irish. But I love him. I'm sure of that now. And he's my country." (435)

Jim's interest in Ireland and his patriotic feelings are provoked by Doyler and their relationship, not disturbed by them. Assuming the story of the Sacred Band of Thebes as a metaphor for their position, he sees no problem in reconciling their burgeoning love with the masculinity performance of a soldier.

Conversely, Doyler's lack of education in Catholic teachings allows him to inspire Jim's abandonment of his religious self-discipline. After the boys make love for the first time, they go to the Easter Mass:

We went to Mass on Easter Sunday. We were at the back with the men and when it came to communion he stood up. He gave such a look at me and said, Come on. I thought, you know, after the night we'd spent. But he was so sure of things. We went up together. I snuck me eyes at him kneeling there. The priest was beside and he had his tongue out waiting. He was so sure everything was right and square. (598)

In both cases a lack of cultural awareness on part of one of the boys allows them both to participate in the masculinity performances in harmony with their stable and coherent identity. This points to the idea that the link between masculinity practices and the rejection of homosexuality is culturally constructed, juxtaposing those practices with the successful masculinity performances of the boys who remain unaware of their exclusion.

There is a last, bitterly ironic twist relevant to the theme of Jim's religiousness. In the final chapters of the novel, the boys take part in the Rising and Doyler dies. Jim, in mourning, revokes his faith: "His rosary beads had dropped by his side and MacMurrough crouched to pick them 
up. 'You can keep them,' the boy said. 'I won't be needing beads no more.'” (640) At first, it was Doyler who prevented Jim from engaging in the masculinity practice of a Catholic man when the boy was preparing to become a Brother of Presentation. Later, however, it was Doyler's example that allowed Jim to negotiate a space between his belief and his sexuality, outside of dogmas discriminating against gay people. Finally, the loss of Doyler is the reason why Jim decides to disengage from the practice altogether; it is not, however, due to any insecurities about his masculinity or his inability to fit into the pattern, but because of a universally human psychological process of questioning one's beliefs after suffering a loss. Ironically, the very same relationship that at first discouraged Jim from joining the clergy was in the end necessary for him to keep believing in God. Jim's sexual and religious identities start as mutually exclusive, but in the course of the novel they become interdependent. This reiterates the idea that love, including homosexual love, can amplify a masculinity performance, rather than render one unable to engage with it.

The boys' eponymous swimming exercise is yet another way in which the novel subverts the juxtaposition of homosexuality and masculinity practices. The boys undertake a heavy regime of physical exercise, which makes their bodies more akin to the ideal, muscled masculine body. On the one hand, this emblem of physical strength and ability is closely linked to the image of masculinity and rooted in a cultural belief that men are stronger and more able to perform physical tasks. On the other, it draws upon the ahistorical position of the author, referring to the post-emancipative gay gym culture, in which a muscled male body has become heavily eroticized, which can be seen in MacMurrough's comment on Doyler: "Swimmer's body, tight, lithe, all of a piece. It really is the best exercise and might be encouraged more among the lower orders as it costs nothing and the effects are wholly benign" (179). The characters throughout the novel go from unconscious appreciation to full acknowledgement of their bodies' aesthetic quality, which for the hegemonic masculinity discourse of the period is irrelevant. The swimming exercise has thus a twofold and unstable meaning, constituting both a masculinity performance, and a gay performance, similar in its rhetorical consequences and possibilities to the way O'Neill deploys the figure of Oscar Wilde.

This duality is reflected in their approach to the exercise. Doyler, who convinces Jim to practice swimming, frames their endeavor with the discourse of nationalism. Their overarching goal becomes reaching Muglins, an island located at a considerable distance from the coast. Doyler makes up a story of two patriots who wanted to claim that land for Ireland, but failed, and now their ghosts haunt the waters. Thus, their regime of exercise is not only a part of the masculinity performance by itself, but it 
is also justified with a nationalist narrative. On the other hand, the journey to Muglins that is the goal of their exercise quickly acquires new meanings. The boys' physical development parallels their sexual awakening, which makes them realize their feelings towards each other. However, Jim decides that only once they achieve their goal can they act upon their desires:

"Come here to me, you gaum."

"No," said Jim. "No," he said again. "I mean it, Doyler, don't."

The shape that had crouched above him stiffened. "No?"

"We can't."...

"Don't you want me, Jim?"

Jim reached his hands to Doyler's shoulders. "Don't you know we have to wait until the island?” (506)

Much as the exercise itself is driven by nationalist ideas but also awakens their romantic and sexual feelings, Muglins, the reason behind these exercises, becomes not only an Irish space they can regain for their country, but also a gay space where they might act upon their feelings. For Jim, who vocalizes this idea, the switch is obvious, and metonymic in its nature; the Irish space is, in his understanding, their space, because in his mindset fighting for Ireland means being with Doyler. Muglins serves as a physical representation of the revolutionary idea that Jim has in mind, one that would create a space for their love.

This metonymic switch is representative of O'Neill's whole rhetorical project in the novel, which involves putting homosexuality in proximity to masculinity performances, presenting the tensions which naturally would arise in early $20^{\text {th }}$-century Irish culture as a result, and slowly diffusing those tensions by exploring the idea that the two are not mutually exclusive. The eponymous boys manage to engage in masculinity practices in a meaningful way, and their same-sex desire does not prevent them from doing so. This is possible partly because they learn about historic practices in which there was no tension at all, and partly because they learn this from one another, as each of them is unaware of an exclusionary practice that blocks the other. This allows them to both experience and understand homophobia as a cultural construct. The novel's historical background makes it an exercise in the very process of reclaiming the history it describes. Drawing on the parallels between Irish history and the gay liberation movement, O'Neill both creates the fictional and reconstructs the historical Irish homosexual contexts. In doing so, the novel repeatedly subverts and dissolves the idea that homosexuality represents a lack of masculinity, along with the cultural meanings and the power relations relying on such an image. 


\section{Works Cited}

Beatty, Aidan. Masculinity and Power in Irish Nationalism, 1884-1938. London: Palgrave Macmillan UK, 2016. Print.

Connell, Raewyn W. Masculinities. Berkeley: U of California P, 2005. Print. Conrad, Kathryn. "Queer Treasons: Homosexuality and Irish National Identity." Cultural Studies 15.1 (2001): 124-37. Abingdon: Routledge. Web. 11 Jan. 2018.

Hall, Donald Eugene. Queer Theories. New York: Palgrave MacMillan, 2003. Print.

Mullen, Patrick R. The Poor Bugger's Tool. New York: Oxford UP, 2012. Print.

O’Neill, Jamie. At Swim, Two Boys. New York: Scribner, 2002. Print.

Jarosław MilewSKi is a PhD student affiliated with the Department of American Literature at the University of Łódź. He is mainly interested in the field of queer studies. He wrote his MA, which received an award from the Institute of English Studies at the University of Łódź, on the political dimension of emancipative gay literature. He presented papers on dual autobiographies, representation of community language in early gay novel, betrayal of witnessing practices in AIDS writing and links between Irish nationalism and homosexuality in Jamie O'Neill's prose. $\mathrm{His} \mathrm{PhD}$ project concerns the literature of AIDS epidemic understood as a practice of witnessing to and dissent from institutions of biopower. jmilewski92@gmail.com 